\title{
Synaptic Differentiation of a Single Motor Neuron: Conjoint Definition of Transmitter Release, Presynaptic Calcium Signals, and Ultrastructure
}

\author{
R. L. Cooper, L. Marin, and H. L. Atwood \\ Department of Physiology, Medical Sciences, University of Toronto, Toronto, Canada M5S-1A8
}

The opener muscle in the walking legs of the crayfish (Procambarus clarkii) is innervated by only one excitatory motor neuron, yet excitatory postsynaptic potentials (EPSPs) of proximal fibers are eightfold larger than those of central muscle fibers at low frequencles of activation, due in large measure to differences in presynaptic properties. We investigated quantal release properties, calcium signals, and ultrastructure of presynaptic terminals to elucidate factors that could account for the physiological differences. Focal macropatch electrodes were placed over individual visualized terminal varicosities to obtain records of quantal contributions to the excitatory junctional current (EJC). At low frequencies of activation, mean quantal content is greater for proximal than for central varicosities. This difference is due to a higher probability of release per synapse, and not to a larger number of active synapses. Recorded varicosities were labeled with fluorescent beads deposited by the electrode. These beads adhered to the muscle fibers, outlining the recorded site for subsequent serial thin sectioning and reconstruction from electron micrographs. Comparisons of structure and function were made for individual varicosities. The number of active zones per terminal surface area and the number of synapses with multiple active zones (complex synapses) were greater in high-output varicosities. Calcium indicators were loaded into proximal and central nerve terminals by axonal injection to compare the relative differences in calcium buildup during stimulation. Presynaptic calcium signals were larger for proximal varicosities than for central varicosities. Since the number of synapses per varicosity is about the same, the difference could arise from a larger number of responsive calcium channels per synapse in proximal varicosities, from possible differences in calcium buffering

\footnotetext{
Received Dec, 14, 1994; revised Feb. 2, 1995; accepted Feb. 3, 1995

We thank Dr. J. M. Wojtowicz for advice on quantal measuring techniques and fruitful discussions, Dr. R. Robitaille for help with calcium imaging, and Mr. T. Goldthorpe for imaging analysis programming. In addition, we thank Ms. M. Hegström-Wojtowicz for technical assistance, and Mrs. H. W. Cooper for illustrative work. Software for off-line analysis measurements was written by Steve Jones, Medical Computing, Medical Sciences, University of Toronto Software for determining values of MLE, AIC, and bootstrapping analysis was provided by Dr. Bruce Smith, University of Victoria, Canada. This work was supported by a Medical Research Council grant (H.L.A.) and by a Network of Centres of Excellence (Canada) postdoctoral fellowship (R.L.C.).

Correspondence should be addressed to Dr. R. L. Cooper, Department of Physiology, Medical Sciences Building, University of Toronto, Toronto, Ontario, Canada MSS-1 A8.

Copyright $(1995$ Society for Neuroscience $\quad 0270-6474 / 95 / 154209-14 \$ 05.00 / 0$
}

mechanisms, or from more pronounced depolarization of proximal terminals.

[Key words: calcium channels, crustacean, synapse, active zones, quantal release, ultrastructure]

Crustacean motor neurons innervate a large number of separate muscle fibers, supplying each with many individual synapses (Wiersma, 1961; Bittner and Kennedy, 1970). The nerve terminals on different muscle fibers are strongly differentiated in their release properties (Iravani, 1965; Atwood, 1967; Bittner, 1968a; Atwood and Bittner, 1971). Such synaptic differentiation appears to be common in many other neural systems, including Ia afferent-motor neuron synapses in the cat spinal cord (Pierce and Mendell, 1993), goldfish Mauthner neurons (Korn et al., 1986), and the autonomic neuromuscular junction in mice (Lavidis and Bennett, 1992). Scveral studics on mammalian central synapses indicate heterogeneity in release probabilities for individual boutons (Hessler et al., 1993; Rosenmund et al., 1993). Although the phenomenon of synaptic differentiation for a single neuron is widespread, it has not been fully investigated, and there are several different hypotheses about it that have yet to be conclusively proved or disproved (Atwood, 1967; Sherman and Atwood, 1972; Zucker, 1974; Parnas et al., 1982a; Zucker and Haydon, 1988; Dudel, 1989a-d; Hochner et al., 1989). Only in a few cases have different terminals of the same single neuron been characterized both physiologically and morphologically (Katz et al., 1993; Walrond et al., 1993) and only recently have individual terminal varicosities of known transmission properties been fully analyzed both physiologically and ultrastructurally (Wojtowicz et al., 1994). Crayfish terminals offer an excellent model for detailed study of the general problem of synaptic differentiation within a single neuron.

The excitatory motor neuron of the opener makes a series of varicosities (Florey and Cahill, 1982), which are easily identified in living preparations with the vital dye 4-Di-2-Asp (Magrassi et al., 1987). This allows placement of a macropatch electrode directly over an isolated varicosity to record synaptic currents and to label it with fluorescent beads. Because these beads are clectron densc and can be visualized with the transmission electron microscope, the marked sites can then be processed for serial sectioning, reconstruction, and ultrastructural analysis (Wojtowicz et al., 1994). In the present study, we reconstructed representative high- and low-output varicosities to determine their complement of synapses and presynaptic active zones.

We compared quantal currents from high- and low-output varicosities. The statistical nature of transmitter release at these junctions has been extensively studied over the years (Dudel and 
Kuffler, 1961; Atwond and Parnas, 1968; Wernig, 1972; Zucker, 1974; Parnas et al., 1982b; Wojtowicz and Atwood, 1984, 1986), but only recently have precise structural correlates been sought at the same sites at which recordings were obtained (Cooper et al., 1993; Wojtowicz et al., 1994). Our evidence indicates that the presynaptic varicosities on the proximal fibers, which generate larger EPSPs, have about a fourfold greater quantal output than those on central fibers. This difference is attributable to larger probabilities of release, rather than to a larger number of synapses. In search of factors that could underlic the difference in probability of release, we measured relative values of $\mathrm{Ca}^{2+}$ buildup in high- and low-output terminals at several different frequencies, and found relatively greater calcium buildup in high-output terminals.

\section{Materials and Methods}

All experiments were performed on the opener muscle of the first and second walking legs in crayfish, Procambarus clarkii, which measured $5-6 \mathrm{~cm}$ in body length (Atchafalaya Biological Supply Co., Raceland, LA). Preparations were dissected and maintained in a modified Van Harreveld's crayfish solution (in mM: $205 \mathrm{NaCl}, 5.3 \mathrm{KCl}, 13.5$ $\mathrm{CaCl}_{2} \cdot 2 \mathrm{H}_{2} \mathrm{O}, 2.45 \mathrm{MgCl}_{2} \cdot 6 \mathrm{H}_{2} \mathrm{O}, 0.5$ HEPES adjusted to $\mathrm{pH} 7.4$ ). During physiological recordings, preparations were superfused with this solution at $14^{\circ} \mathrm{C}$

Anatomy and general physiology. The overall anatomy and innervation of the ventral surface of the opener muscle was visualized by applying the vital dye 4-Di-2-Asp [4-(4-diethylaminostyryl)- $N$-methylpyridinium iodide] (Molecular Probes, Eugene, OR) at a final concentration of $5 \mu \mathrm{M}$ for 2 min followed by washing in crayfish solution.

The opener muscle can be subdivided into three distinct regions (proximal, central, and distal) on the basis of muscle fiber diameter, length, and orientation, as shown schematically in Figure 1. Selective isolation of the excitatory axon was carried out as described by Dudel and Kuffler (1961). Average excitatory postsynaptic potentials (EPSPs) were measured in central and proximal muscle fibers from several preparations by stimulating the excitatory motor neuron 200 times at $1 \mathrm{~Hz}$.

Synaptic currents. Synaptic currents were recorded through a macropatch electrode as described by Dudel (1981) and Wojtowicz et al. (1991). Electrodes were made from Kimax glass (1.5 mm o.d.) that was pulled and fire polished to produce tips with inside diameters ranging from 10 to $20 \mu \mathrm{m}$. All recordings were obtained in crayfish solution with macropatch electrodes filled with the same solution. The patchclamp amplifier was obtained from Zeitz-Instrumente Vertriebs GmbH (Augsburg, Germany). Electrode and seal resistances were determined by passing test current pulses through the electrode. Seal resistances ranged from 0.3 to $1.0 \mathrm{M} \Omega$ and the resistances of electrodes ranged from 0.5 to $1.0 \mathrm{M} \Omega$ When synaptic currents were compared between recording sites, electrode and seal resistances were taken into account as described by Stühmer and Almers (1982).

Terminal varicosities were visualized with the vital fluorescent dye 4-Di-2-Asp (Magrassi ct al., 1987) to achieve placement of the lumen of the electrode directly over a single varicosity. Minimal staining and observation times under fluorescence were used to reduce possible damaging effects. Each preparation was stained for $2 \mathrm{~min}$ at $5 \mu \mathrm{M}$. To test the effects of dye on quantal release, we conducted several experiments in which synaptic currents were recorded in the absence of the dye and later after applying the dye to the preparation. A recording site was located first without using the dye, by placing the macropatch electrode on the muscle close to primary branches from the main axon where innervation is commonly found. After a few trials, a site giving good quantal currents was selected. After recordings from this site had been made, the vital dye was added to the bath until the terminals under the macropatch electrode stained as observed in prior experiments. Then, the nerve was stimulated again. In three experiments judged to be reliable, mean quantal content remained the same after staining (Table 1). Thus, under the conditions of staining and illumination that we employed, the dye had no evident effects on synaptic transmission for the duration of the experiments. However, with more prolonged or intense illumination, deleterious effects on mitochondria and ultimately on synaptic transmission ensue.

Stimuli were given at $1 \mathrm{~Hz}, 5 \mathrm{~Hz}$, and $10 \mathrm{~Hz}$ to the isolated motor neuron while recording over a varicosity. Seal resistances were moni-

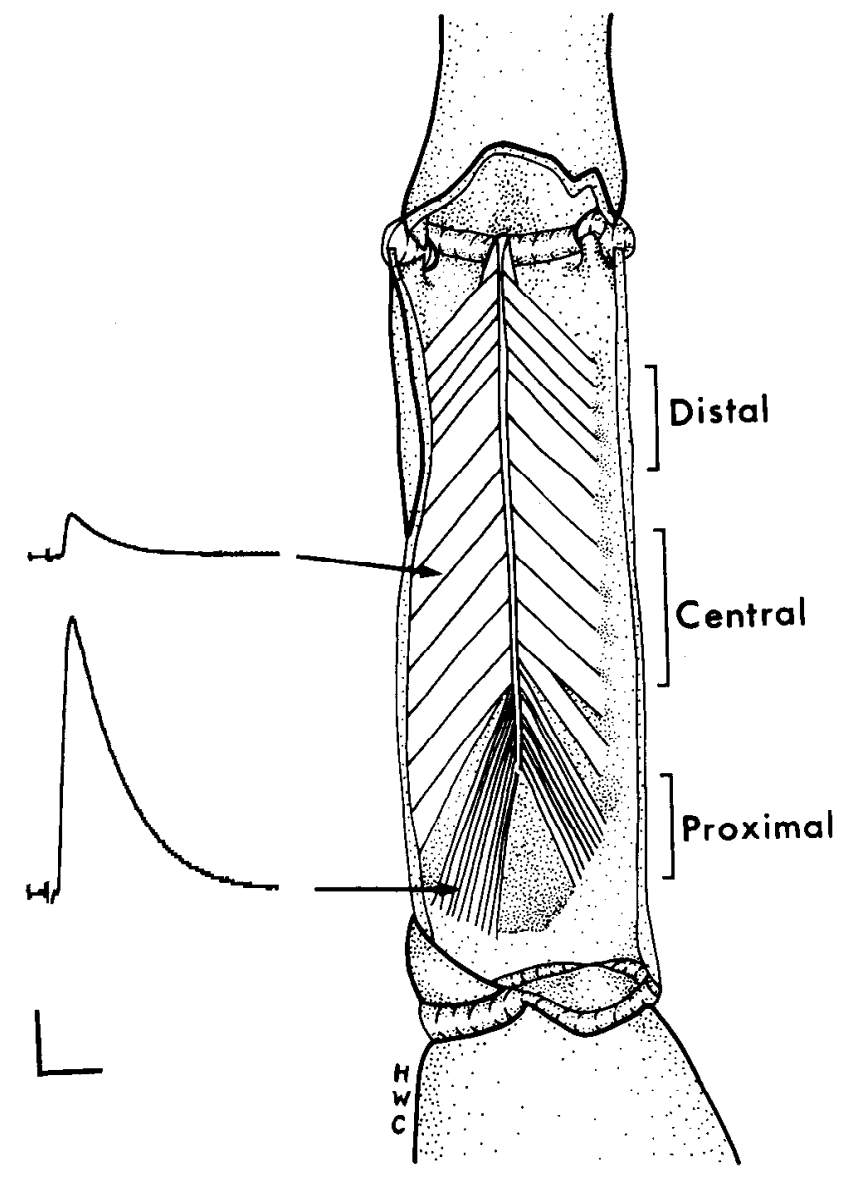

Figure 1. A schematic of the opener muscle showing three regions, which can he distinguished by the relative diameters and lengths of the fibers. Muscle fibers are labeled and their differences in diameters are slightly exaggerated to illustrate the differences. Averaged $(n=500$ sweeps) excitatory postsynaptic potentials (EPSPs) recorded with intracellular electrodes during stimulation of the excitatory motor axon at 1 $\mathrm{Hz}$ are shown for representative proximal and central muscle fibers. Calibration: $0.4 \mathrm{mV}, 50 \mathrm{msec}$.

tored throughout the recording. If seal resistance varied, then the data set was not utilized; this was often the case while recording from proximal muscle fibers during $10 \mathrm{~Hz}$. stimulation, due to muscle contraction.

Mean quantal content $(m)$ was determined at $1 \mathrm{~Hz}$ by counting the number of individual quantal responses in each sweep during the experiment (Martin, 1977; Wojtowicz et al., 1991). For each trial, the number of sweeps ranged from 500 to 1000 . The data acquisition rate was set at $16.67 \mathrm{kHz}$. At stimulation frequencies of 5 and $10 \mathrm{~Hz}$ discrete quantal events could not be unambiguously and consistently discerned. At these frequencies, $m$ was determined by charge measurements (Bekkers and Stevens, 1991; Cooper et al., 1995). Values for charge (pA-msec) of individual events were obtained by integrating the current trace (Bekkers and Stevens, 1991; Van der Kloot, 1991). Charge measurements are preferable to amplitude measurements because they are less subject to errors arising from variation in latency of release that is commonly observed at the crayfish neuromuscular junction, even at low frequencies of stimulation (Wojtowicz and Atwood, 1986). A preliminary report has been presented on this matter (Stewart et al., 1994) and a detailed study of quantal analysis methods in various preparations has been completed (Cooper et al., 1995). The values for mean charge of evoked $\left(\overline{\mathrm{a}}_{\mathrm{ch}}\right)$ and spontaneous events $\left(\overline{\mathrm{q}}_{\mathrm{ch}}\right)$ then provide an estimate for mean quantal content, calculated as $m_{\mathrm{ch}}=\overline{\mathrm{a}}_{\mathrm{ch}} / \overline{\mathrm{q}}_{\mathrm{ch}}$. The window of time chosen to measure evoked responses was obtained from the averaged trace, starting just prior to the averaged evoked response and ending at the point at which the current returned to baseline. Values for $\bar{a}_{\text {ch }}$ were derived from 500-1000 trials, and values for $\mathrm{q}_{\mathrm{ch}}$ from at least 30 individual events. 
Table 1. Effects of applying the vital dye (4-Di-2- $\Lambda$ sp) on quantal parameters

\begin{tabular}{|c|c|c|c|c|c|}
\hline \multicolumn{5}{|c|}{ Distribution } & Quanta \\
\hline Exp. & Evts. & Obs. & Best fit & $x^{2}$ & $(m)$ \\
\hline \multicolumn{6}{|c|}{ Before staining } \\
\hline \multirow[t]{2}{*}{1} & 0 & 481 & 481 & & 0.04 \\
\hline & 1 & 19 & $\begin{array}{l}19 \\
\text { uniform }\end{array}$ & 0 & \\
\hline \multirow[t]{3}{*}{2} & 0 & 395 & 396 & & 0.21 \\
\hline & 1 & 104 & 104 & 0.002 & \\
\hline & 2 & 1 & $\begin{array}{c}0 \\
\text { uniform }\end{array}$ & & \\
\hline \multirow[t]{3}{*}{3} & 0 & 452 & 455 & & 0.12 \\
\hline & 1 & 55 & 55 & 0.002 & \\
\hline & 2 & 3 & $\begin{array}{c}0 \\
\text { uniform }\end{array}$ & & \\
\hline \multicolumn{6}{|c|}{ After staining } \\
\hline \multirow[t]{2}{*}{1} & 0 & 474 & 474 & & 0.05 \\
\hline & 1 & 26 & $\begin{array}{l}26 \\
\text { uniform }\end{array}$ & 0 & \\
\hline \multirow[t]{3}{*}{2} & 0 & 405 & 405 & & 0.20 \\
\hline & 1 & 92 & 92 & 0 & \\
\hline & 2 & 3 & $\begin{array}{l}3 \\
\text { nonuniform }\end{array}$ & & \\
\hline \multirow[t]{3}{*}{3} & 0 & 462 & 465 & & 0.10 \\
\hline & 1 & 45 & 45 & 0.006 & \\
\hline & 2 & 3 & $\begin{array}{c}0 \\
\text { uniform }\end{array}$ & & \\
\hline
\end{tabular}

Quantal release was recorded before and after staining with the vital dye (4Di-2-ASP) for terminals on central muscle fibers at $1 \mathrm{~Hz}$ nerve stimulation. Observed quantal counts and estimated best fits to the observed distributions are given along with the $\chi^{2}$ (one-sample test) values indicating the goodness of the predicted fit. Mean quantal content $(m)$ is also listed for each experiment. Exp., experiment number; Evts., the number of discrete events, indicated as 0 $=$ failure, 1 = one, 2 = Iwo, etc.; Obs., the observed occurrences of each event. An indication of whether the distribution conforms best to a uniform or nonuniform binomial distribution is included.

For assessment of the degree of change in $m_{\mathrm{ch}}$ with increasing stimulation frequency, the percentage difference in the response was determined. This procedure normalized each recording site so that relative comparisons could conveniently be made. The percentage difference in $m_{\mathrm{ch}}$ is calculated as follows:

$$
\% \text { difference in } m_{\mathrm{ch}}=\left[\left(m_{\mathrm{ch} b}-m_{\mathrm{cha} a}\right) / m_{\mathrm{ch} a}\right](100 \%) \text {, }
$$

where $m_{\mathrm{ch} b}$ is the calculated mean quantal content at a higher frequency of stimulation, and $m_{\mathrm{cha}}$ is the calculated mean quantal content at a lower frequency.

Quantal parameters. To determine whether synaptic efficacy per varicosity is different for terminals of proximal and central muscle fibers, we counted the occurrences of failures and successful synaptic events during $1 \mathrm{~Hz}$ stimulation (Tables 2,3). The observed distributions were utilized as initial parameters to determine whether a uniform binomial, nonuniform binomial, or Poisson model best fitted the data set. A modified Akaike information criterion (AIC) was used to select the bestfitted model from the minimized $\chi^{2}$ statistic (Smith et al., 1991; Wojtowicz et al., 1994). A one-sample $\chi^{2}$ test was used for each data set to determine how well the observed distributions fit the predicted models.

Representative values for $n$ and $p$ were obtained from maximum likelihood estimation (MLE), previously described in detail (Smith et al., 1991; Wojtowicz et al., 1991, 1994). To ascertain whether the derived $n$ and $p$ values are representative of the possible values, we calculated standard errors for these values by a "bootstrapping" approach (Efron, 1979; Efron and Tibshirani, 1993; Wojtowicz et al., 1994). The derived $n$ and $p$ values are reported along with the calculated standard errors in Tables 2 and 3 .

Reconstruction of recorded sites. The macropatched site from which recordings were obtained was marked by fluorescent beads. This was done by dipping the tip of an electrode into a slurry of fluorescent polystyrene beads $(0.5 \mu \mathrm{m}$ diameter, Duke Scientific Co.) a few times with air drying between dips, and then backfilling the electrode under pressure with crayfish solution to ensure that the lumen of the electrode was free of the beads. Thus, beads adhered only to the rim and outer walls of the electrode (Fig. $2 A$ ). This is a modification of the procedure previously reported by Wojtowicz et al. (1994), for which the beads were mixed with the recording solution in the lumen of the electrode.

When the recording session was over, the beaded macropatch electrode was raised off the surface of the muscle, leaving usually a distinct ring of fluorescent beads (see Fig. $6 \mathrm{~A}$ ). The tissue was rapidly processed for electron microscopy (Jahromi and Atwood, 1974; Wojtowicz et al., 1994). The fluorescence of the beads persists even after fixation, osmium treatment, and resin embedding of the specimen, but dehydration must be carried out entirely in ethanol, to avoid dissolving the beads. These beads are moderately electron dense and can be easily visualized in thin sections. The entire area within a bead ring was serially sectioned ( $\sim 300$ sections). Sections were collected on Formvar-coated slotted grids. Some loss of sections occurred during staining and washing procedures due to separation of the Formvar from the slotted grids. Keconstructions were made using HVEM 3-D software (Young et al., 1987) along with a Digi-Pad 5 (GTCO Corp.) digitizing tablet. A log of each serial section was kept and the thickness was determined by inference colors of the sections while they were floating on the surface of water after sectioning. Sections were for the most part consistently cut at 75 $\mathrm{nm}$. Synaptic area was determined by tracing the synaptic sites on electron micrographs (see Fig. $5 \mathrm{C}$ ) in each serial section with the use of the digitizing tablet. From the section thickness and the length of a synapse in each section, synaptic area was calculated by adding the values for all sections of that synapse in the series. Quantitative morphological data obtained from these reconstructions were compared for the different specimens by calculating the ratios or the percentage differences of the measurements (Wojtowicz et al., 1994). Synaptic contacts and associated presynaptic dense bodies (active zones) were designated and measured (Govind et al., 1994). Terminal length measurements included separate measurements for any branches, which occurred in the reconstruction of the proximal varicosity. Total terminal length was derived by counting the number of sections for an individual terminal and multiplying by the section thickness. If a section was lost during poststaining, the thickness of the missing section was included in the overall terminal measurements. This was also the way in which synaptic area was calculated in the cases of a single lost section within a synaptic region. In these cases, synapses were still considered complete, since their area could be accurately determined by extrapolation from the adjacent sections. If a synapse extended beyond the recorded and labeled terminal region, the measurement of synaptic area was terminated at this point. This produced synapses that were incomplete in reconstruction. In such cases, some synapses would be considered "incomplete" and were pooled in a separate category.

Calcium imaging. Relative measurements of $\mathrm{Ca}^{2+}$ were made with two $\mathrm{Ca}^{2+}$-sensitive indicators: calcium green $2\left(K_{d}=0.574 \mu \mathrm{M}\right)$, and calcium green $5 \mathrm{~N}\left(K_{d}=3.3 \mu \mathrm{M}\right)$ (Molecular Probes). These indicators helped assess the rclative differences in $\mathrm{Ca}^{3+}$ concentrations within the nerve terminal during a stimulation paradigm. They were made to a concentration of $5 \mathrm{mM}$ in $400 \mathrm{mM} \mathrm{KCl}$ before backfilling microelectrodes (Omega dot fiber, $1.2 \mathrm{~mm}$ o.d: $\times 0.9 \mathrm{~mm}$ i.d.; $20-30 \mathrm{M} \Omega$ ), and were iontophoretically injected into secondary branches of the main axon in both central and proximal regions of the muscle.

Fluorescence measurements were obtained with a Bio-Rad MRC 600 confocal laser microscope using a $40 \times(0.55$ NA) Nikon water immersion objective. The laser beam was attenuated to $1 \%$ with a neutral density filter before passing through a blue excitation filter $(488 \mathrm{~nm})$. Emitted fluorescence was detected using a low-pass emission filter (515 $\mathrm{nm})$.

The excitatory motor axon terminals of interest were imaged consecutively (8-16 times) before and during each $2.5 \mathrm{~Hz}, 5 \mathrm{~Hz}$, or $10 \mathrm{~Hz}$ stimulation period. Each imlage $(191 \times 127$ pixels $)$ took approximately $250 \mathrm{msec}$ to capture to disk. An average of plateaus in the fluorescence signal was taken for each stimulation frequency. The fluorescence of each varicosity is expressed as a change in fluorescence over the resting fluorescence (Robitaille and Charlton, 1992): 
Table 2. Statistics of evoked quantal release at single boutons on central muscle fibers

\begin{tabular}{|c|c|c|c|c|c|c|}
\hline \multicolumn{5}{|c|}{ Distribution } & \multirow{2}{*}{$\begin{array}{l}n( \pm \mathrm{SE}) \\
p( \pm \mathrm{SE})\end{array}$} & \multirow{2}{*}{$\begin{array}{l}\text { Quantal } \\
\text { content } \\
(m)\end{array}$} \\
\hline Exp. & Evts. & Obs. & Best fit & $\chi^{2}$ & & \\
\hline \multirow[t]{3}{*}{1} & 0 & 301 & 301 & & $2 \pm 0$ & 0.422 \\
\hline & 1 & 187 & 187 & 0 & $0.21 \pm 0.012$ & \\
\hline & 2 & 12 & $\begin{array}{l}12 \\
\text { nonuniform }\end{array}$ & & & \\
\hline \multirow[t]{3}{*}{2} & 0 & 384 & 384 & & $3 \pm 0$ & 0.254 \\
\hline & 1 & 105 & 105 & 0 & $0.09 \pm 0.038$ & \\
\hline & 2 & 11 & $\begin{array}{l}11 \\
\text { uniform }\end{array}$ & & & \\
\hline \multirow[t]{4}{*}{3} & 0 & 465 & 465 & & $>7$ & 0.08 \\
\hline & 1 & 30 & 34 & 16 & very low & \\
\hline & 2 & 5 & 1 & & & \\
\hline & & & Poisson & & & \\
\hline \multirow[t]{5}{*}{4} & 0 & 394 & 374 & & $>20$ & 0.29 \\
\hline & 1 & 105 & 109 & 3.7 & very low & (site $\mathrm{C} 2$ ) \\
\hline & 2 & 21 & 16 & & & \\
\hline & 3 & 0 & 2 & & & \\
\hline & & & Poisson & & & \\
\hline \multirow[t]{4}{*}{5} & 0 & 284 & 283 & & $3 \pm 0.89$ & 0.524 \\
\hline & 1 & 173 & 175 & 0 & $0.18 \pm 0.031$ & (site $\mathrm{C} 1$ ) \\
\hline & 2 & 40 & 38 & & & \\
\hline & 3 & 3 & $\begin{array}{c}4 \\
\text { uniform }\end{array}$ & & & \\
\hline \multirow[t]{4}{*}{6} & 0 & 710 & 710 & & $2 \pm 0.589$ & 0.32 \\
\hline & 1 & 260 & 260 & 0 & $0.16 \perp 0.027$ & \\
\hline & 2 & 30 & 30 & & & \\
\hline & & & nonuniform & & & \\
\hline \multirow[t]{4}{*}{7} & 0 & 383 & 383 & & $2 \pm 1.8$ & 0.25 \\
\hline & 1 & 109 & 109 & 0 & $0.13 \pm 0.26$ & \\
\hline & 2 & 8 & 8 & & & \\
\hline & & & uniform & & & \\
\hline \multirow[t]{4}{*}{8} & 0 & 843 & 843 & & $2 \pm 2.715$ & 0.17 \\
\hline & 1 & 150 & 150 & 0 & $0.08 \pm 0.02$ & \\
\hline & 2 & 7 & 7 & & & \\
\hline & & & uniform & & & \\
\hline \multirow[t]{6}{*}{9} & 0 & 814 & 792 & & $>50$ & 0.217 \\
\hline & 1 & 159 & 185 & 4.3 & very low & \\
\hline & 2 & 24 & 23 & & & \\
\hline & 3 & 2 & 2 & & & \\
\hline & 4 & 1 & 0 & & & \\
\hline & & & Poisson & & & \\
\hline \multirow[t]{4}{*}{10} & 0 & 675 & 675 & & $2 \pm 0$ & 0.346 \\
\hline & 1 & 304 & 304 & 0 & $0.17 \pm 0.008$ & \\
\hline & 2 & 21 & 21 & & & \\
\hline & & & nonuniform & & & \\
\hline \multirow[t]{4}{*}{11} & 0 & 946 & 934 & & $>50$ & 0.064 \\
\hline & 1 & 54 & 64 & 6.12 & very low & \\
\hline & 2 & 5 & 2 & & & \\
\hline & & & Poisson & & & \\
\hline \multirow[t]{2}{*}{12} & 0 & 949 & 949 & & $1+0$ & 0.51 \\
\hline & 1 & 51 & $\begin{array}{l}51 \\
\text { uniform }\end{array}$ & 0 & $0.05 \pm 0.007$ & \\
\hline \multirow[t]{4}{*}{13} & 0 & 903 & 904 & & $4 \pm 7.15$ & 0.116 \\
\hline & 1 & 96 & 96 & 0.001 & $0.03 \pm 0.017$ & \\
\hline & 2 & 0 & 0 & & & \\
\hline & 3 & 1 & $\begin{array}{c}0 \\
\text { nonuniform }\end{array}$ & & & \\
\hline
\end{tabular}


Table 2. Continued

\begin{tabular}{|c|c|c|c|c|c|c|}
\hline \multicolumn{5}{|c|}{ Distribution } & \multirow{2}{*}{$\begin{array}{l}n( \pm \mathrm{SE}) \\
p( \pm \mathrm{SE})\end{array}$} & \multirow{2}{*}{$\begin{array}{l}\text { Quantal } \\
\text { content } \\
(m)\end{array}$} \\
\hline Exp. & Evts. & Obs. & Best fit & $\chi^{2}$ & & \\
\hline \multirow[t]{3}{*}{14} & 0 & 901 & 901 & & $2 \pm 3.6$ & 0.101 \\
\hline & 1 & 97 & 97 & 0 & $0.05 \pm 0.014$ & \\
\hline & 2 & 2 & 2 & & & \\
\hline
\end{tabular}

$15 \quad 0 \quad 91$

nonuniform

$1 \quad 70$

$2 \quad 14$

32 No fit

42 satisfactory

Mean $( \pm \mathrm{SE})$,

$0.253( \pm 0.039)$

Quantal parameters were calculated for central terminals by direct counts of released quanta at $1 \mathrm{~Hz}$ stimulation. Observed quantal counts, mean quantal content $(m)$, and estimated best fits to the observed distributions are given along with the $\chi^{2}$ (one-sample test) values indicating the goodness of the predicted fit. Exp., experiment number; Evts., the number of discrete events, indicated as $0=$ failures, $1=$ one, $2=$ two, etc.; Obs., the observed occurrences of each event.

Table 3. Statistics of evoked quantal release at single boutons on proximal muscle fibers

Distribution

\begin{tabular}{|c|c|c|c|c|c|c|}
\hline \multicolumn{5}{|c|}{ Distribution } & \multirow{2}{*}{$\begin{array}{l}n( \pm \mathrm{SE}) \\
p( \pm \mathrm{SE})\end{array}$} & \multirow{2}{*}{$\begin{array}{l}\text { Quantal } \\
\text { content } \\
(m)\end{array}$} \\
\hline Exp. & Evts. & Obs. & Best fit & $\chi^{2}$ & & \\
\hline \multirow[t]{5}{*}{1} & 0 & 156 & 156 & & $3 \pm 0$ & 1.07 \\
\hline & 1 & 579 & 579 & 0 & $0.36 \pm 0.007$ & (site P1) \\
\hline & 2 & 207 & 207 & & & \\
\hline & 3 & 8 & 8 & & & \\
\hline & & & nonuniform & & & \\
\hline \multirow[t]{6}{*}{2} & 0 & 126 & 126 & & $4 \pm 0$ & 1.22 \\
\hline & 1 & 510 & 509 & 2.12 & $0.31 \pm 0.006$ & \\
\hline & 2 & 294 & 291 & & & \\
\hline & 3 & 18 & 23 & & & \\
\hline & 4 & 2 & 1 & & & \\
\hline & & & nonuniform & & & \\
\hline \multirow[t]{5}{*}{3} & 0 & 54 & 54 & & $3+0$ & 1.3 \\
\hline & 1 & 614 & 614 & 0 & $0.43 \pm 0.006$ & \\
\hline & 2 & 307 & 307 & & & \\
\hline & 3 & 25 & 25 & & & \\
\hline & & & nonuniform & & & \\
\hline \multirow[t]{5}{*}{4} & 0 & 300 & 300 & & $3 \pm 0$ & 0.792 \\
\hline & 1 & 610 & 610 & 0 & $0.26 \pm 0.007$ & \\
\hline & 2 & 88 & 88 & & & \\
\hline & 3 & 2 & 2 & & & \\
\hline & & & nonuniform & & & \\
\hline \multirow[t]{4}{*}{5} & 0 & 367 & 367 & & $2 \pm 0$ & 0.696 \\
\hline & 1 & 570 & 570 & 0 & $0.35 \pm 0.009$ & \\
\hline & 2 & 63 & 63 & & & \\
\hline & & & nonuniform & & & \\
\hline \multirow[t]{7}{*}{6} & 0 & 529 & 529 & & $3 \pm 0$ & 0.533 \\
\hline & 1 & 410 & 410 & 0 & $0.18 \pm 0.007$ & \\
\hline & 2 & 60 & 60 & & & \\
\hline & 3 & 1 & 1 & & & \\
\hline & & & nonuniform & & & \\
\hline & & & & & & Mean $( \pm S E)$ \\
\hline & & & & & & $0.94( \pm 0.13)$ \\
\hline
\end{tabular}

Quantal parameters were calculated for proximal terminals by direct counts of released quanta at $1 \mathrm{~Hz}$ stimulation, as in Table 1 . 
A

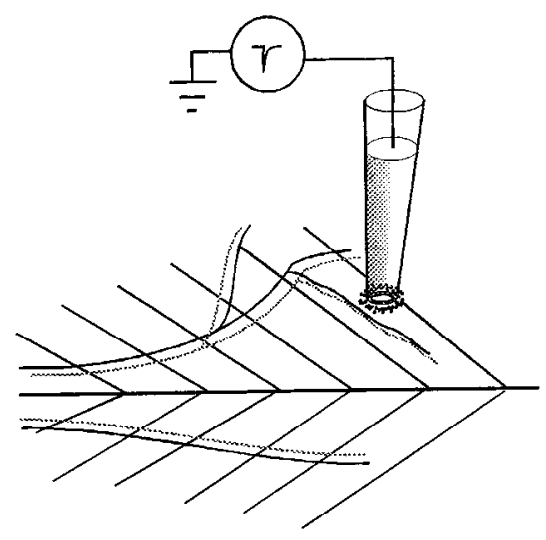

Figure 2. Experimental arrangement and typical recordings of synaptic currents in the proximal and central regions of the opener muscle. $A$, Experimental arrangement for recording and labeling the area that is under the macropatch electrode. The solid (excitatory) and dashed (inhibitory) lines represent the terminal innervation over which the electrode is placed. $B$, Synaptic events that are typically observed at visualized varicosities with macropatch electrodes. In this example, two discrete evoked events can be observed. The test pulse $(T P)$ is always recorded throughout the experiment to monitor electrode and seal resistance. $C$ and $D$, Average (1000 sweeps) synaptic currents from a central ("low-output") varicosity $(C)$ and from a proximal ("high-output") varicosity $(D)$, at different frequencies. Arrows indicate the stimulus artifact; the asterisks indicate the evoked nerve terminal action potential. Calibration: $0.2 \mathrm{nA}, 5 \mathrm{msec}$ $(D$ also for $C)$.
B
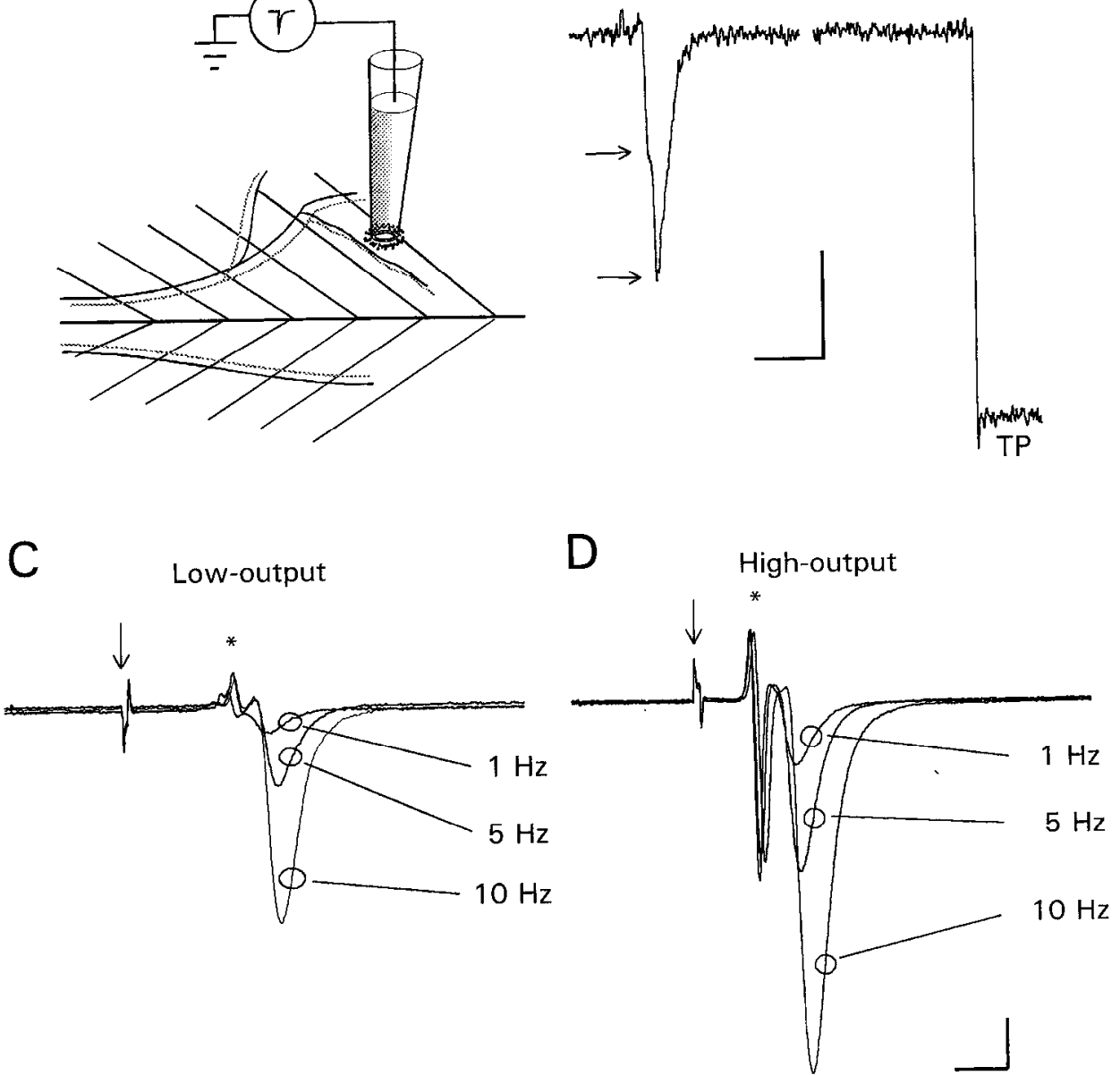

$$
\Delta F / F=\left(F_{\text {Stimulation }}-F_{\text {Rest }}\right) / F_{\text {Rest }}
$$

Fluorescence measurements were made by outlining a varicosity and obtaining an average intensity. Each image of a given varicosity obtained during the control and stimulation paradigms was measured using the same outlined area (Bio-Rad software).

Fluo-3 AM, which works well for frog motor nerve terminals (Robitaille and Charlton, 1992), was also tried. Crayfish motor nerve terminals load with this indicator, and changes in fluorescence can be observed upon electrical stimulation of the neuron. But, because of the rapid rate of fading of the fluorescence signal, which was not constant from preparation to preparation, it was nearly impossible to obtain meaningful data. The manufacturer's catalog (Molecular Probes, 19921994) notes that the calcium green $\mathrm{Ca}^{2+}$ indicators do not bleach as rapidly as Fluo-3 and provide, as well, a higher resting fluorescence signal. Thus, the calcium green indicators were used for the present experiments.

\section{Results}

\section{Innervation of the opener muscle}

The opener muscle is innervated over its entire surface by one excitatory motor neuron and one inhibitory motor neuron, with an additional common inhibitory motor neuron innervating relatively few muscle fibers in the proximal end of the muscle (Wiens, 1985). The muscle's general morphology is schematically illustrated in Figure 1. Measuring EPSPs in various locations across the ventral surface of the muscle revealed a striking difference in amplitude of the response. Average EPSP amplitudes of single proximal muscle fibers are commonly eight times larger than those in central muscle fibers (Fig. 1). These obser- vations confirm in general earlier reports by Iravani (1965), Bittner (1968a,b), Linder (1974), and Thompson and Atwood (1984).

The innervation of the different regions of the opener muscle's inner surface can be characterized on the basis of the degree of branching and length of the terminals (Atwood et al., 1994). Preliminary evidence indicates that the extent of terminal branching and the number of varicosities per muscle fiber are less on the high-output proximal muscle fibers than on lowoutput central fibers (Harrington, 1993; Govind et al., 1994). The terminals on central muscle fibers generally are present as long strings of varicosities. The varicosities decrease in size from proximal to distal locations along a string. On the proximal muscle fibers, the tcrminals also may appcar as strings of varicosities but they are usually more compactly clustered close to the prominent axon branches (Harrington, 1993; Delaney and Tank, 1994; Govind et al., 1994).

\section{Quantal events at single varicosities}

The anatomical data and EPSP differences indicate that the quantal output is greater on average for an individual varicosity on proximal than on central muscle fibers. To test for this possibility, we recorded focal synaptic currents over various spatially separated varicosities in these regions. Figure $2 B$ illustrates synaptic currents recorded with a focal macropatch electrode placed directly over a representative single varicosity visualized 

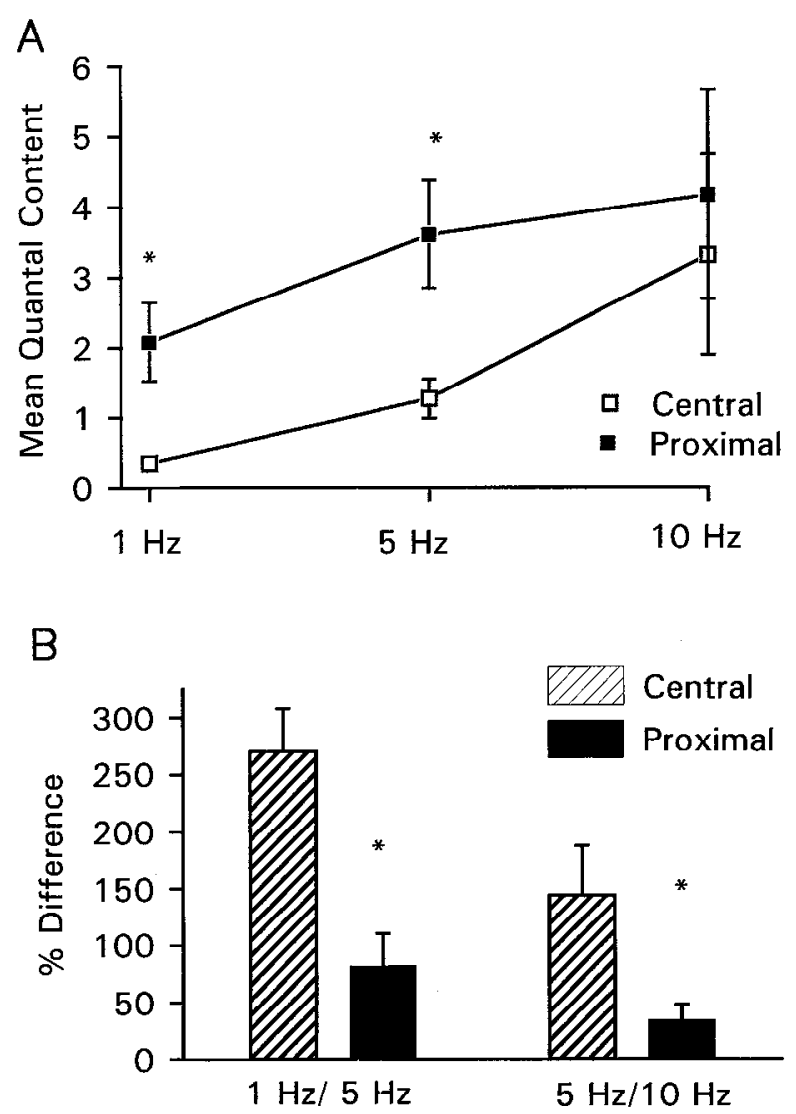

Figure 3. Mean quantal content recorded over several varicosities from proximal and central muscle fibers. $A$, Mean quantal content ( $\pm \mathrm{SE}$ ) as a function of stimulation frequency calculated from charge measurements $(*$, significant difference between the two regions at 1 $\mathrm{Hz}$ and $5 \mathrm{~Hz}, p<0.05, t$ test). $B$, Percentage difference in mean quantal current for proximal $(n=6)$ and central terminals $(n=6)$, from $1 \mathrm{~Hz}$ to $5 \mathrm{~Hz}$ and from $5 \mathrm{~Hz}$ to $10 \mathrm{~Hz}$ stimulation $\left(^{*}\right.$, significant difference between the two regions for both comparisons; $p<0.05, t$ test).

after staining with 4-Di-2-Asp. Discrete evoked quantal events are discernable at this low stimulation frequency of $1 \mathrm{~Hz}$. Averaged evoked synaptic currents produced at stimulation frequencies of $1 \mathrm{~Hz}, 5 \mathrm{~Hz}$, and $10 \mathrm{~Hz}$ from proximal (high-output) and central (low-output) terminals are shown in Figure 2, $C$ and $D$. These current records are corrected for electrode and seal resistance (see Materials and Methods). Mean quantal content obtained from direct counts at $1 \mathrm{~Hz}$ and quantal contents obtained from synaptic charge measurements $\left(m_{\mathrm{ch}}\right)$ during $1 \mathrm{~Hz}, 5$ $\mathrm{Hz}$, and $10 \mathrm{~Hz}$ stimulation were determined for terminals located on proximal and central muscle fibers in several preparations. We compared the percentage difference in $m_{\mathrm{ch}}$ at different selected stimulation frequencies for varicosities on central and proximal fibers (Fig. 3). From $1 \mathrm{~Hz}$ to $5 \mathrm{~Hz}$, the percentage difference in $m_{\mathrm{ch}}$ increased by $100 \%$ in proximal terminals, whereas in the central terminals the increase was over $200 \%$ ( $p$ $<0.05, t$ test, $n=6$ at both sites). The change was not as great for either proximal or central terminals when the stimulation was increased from $5 \mathrm{~Hz}$ to $10 \mathrm{~Hz}$. It is apparent from the results that synaptic transmission can be increased to a greater extent in central terminals than in proximal terminals with increasing frequency. These findings are in accord with those of earlier investigations (Iravani, 1965; Linder, 1974; Govind et al., 1994).

\section{Quantal parameters}

The average mean quantal content, obtained by direct counts of individual quantal events $(m)$ at a stimulation frequency of $1 \mathrm{~Hz}$, is less for varicosities on central fibers $(0.235 \pm 0.04$, mean \pm SE) than those on proximal fibers $(0.94 \pm 0.13 ; p<0.05, t$ test) (Tables 2, 3). Comparison of mean quantal contents from counts of discrete quantal events, and those obtained from charge measurements $\left(m_{\mathrm{ch}}\right)$ (Fig. 3), yields the same conclusions. Values for both $m$ and $m_{\mathrm{ch}}$ are larger for varicosities on proximal fibers than for those on central fibers $(p<0.05$ in both cases for the two methods of measurement). Thus on average, more quanta are released per impulse at $1 \mathrm{~Hz}$ from terminal varicosities on proximal fibers than for those on central fibers (Tables 2, 3).

The best-fitted distributions for the number of discrete evoked events indicate that release can be well described, in most cases, by one of the distribution models (uniform binomial, nonuniform binomial, or Poisson). However, the fits for Poisson distributions were always less good than for the binomial distributions. The central terminals showed an equal occurrence of uniform and nonuniform binomial distributions, as well as four cases in 14 experiments in which the Poisson distributions provided the best fit, whereas the proximal terminals all displayed nonuniform binomial distributions. The estimated mean $p$ values of release for either of the two binomial distributions indicate that the highoutput terminals have a greater probability of release than lowoutput terminals at the same stimulation frequency, while there is no significant difference in the estimated $n$ values of the two regions. The average $p$ for high-output terminals is 0.315 (SE 0.35 ), and for the low-output terminals, 0.115 (SE 0.02); these values are significantly different $(p<0.001 ; t$ test). Standard errors and discrete probability values could not be estimated for the Poisson distributions. These results suggest that synaptic release sites in the high-output terminals have a greater average probability of release at low frequencies of activation. This gives more transmission for a single terminal action potential, and contributes to a larger amplitude of the EPSP.

\section{Ultrastructure}

To determine whether differences in synaptic output could be due to detectable anatomical features at synaptic sites, we undertook serial reconstructions of recorded sites. Several criteria have to be met (Wojtowicz et al., 1994) before and after the tissue is processed for electron microscopy to render reconstruction useful. In brief, the electrical recording must be effective enough to detect unitary quantal events above the noise level and to produce a sufficient number of them for statistical analysis. Also, the electrode and seal resistances must be maintained throughout the recording period to ensure stationarity. For labeling of the recorded site, an intact ring of fluorescent beads must be visualized before and after fixation and embedding of the tissue. The most tenuous aspect is to serial-section the entire labeled site with minimal loss of sections.

The prestaining with the vital dye 4-Di-2-Asp helped in placing the macropatch electrode directly over a visible varicosity for recording and labeling with fluorescent beads (see Materials and Methods) as shown in Figure $6 A$ (C1). The yellow ring is made up of many beads that adhered to the muscle. Most of the ring is out of the plane of focus to emphasize a terminal varicosity located directly in the center of the ring of beads. One reconstructed varicosity (P1) is from a terminal that was located 
Figure 4. Schematic representation of the locations at which recordings were made from varicosities that were subsequently reconstructed from serial electron microscopy sections. Site $P 1$, A varicosity located on a terminal branch of the proximal region, close to a prominent secondary axon branch. Site $C 1$ and Site $C 2$, Strings of varicosities and recording sites on central muscle fibers. Site $\mathrm{Cl}$, Demarcation of a recording site at a varicosity close to the axon branch. Site $C 2$, Recording site at a varicosity mid-way along a string. These terminals were traced from composites of photographs taken at several focal planes. Scale bar, 50 $\mu \mathrm{m}$.

\section{Site P1}

Site C1

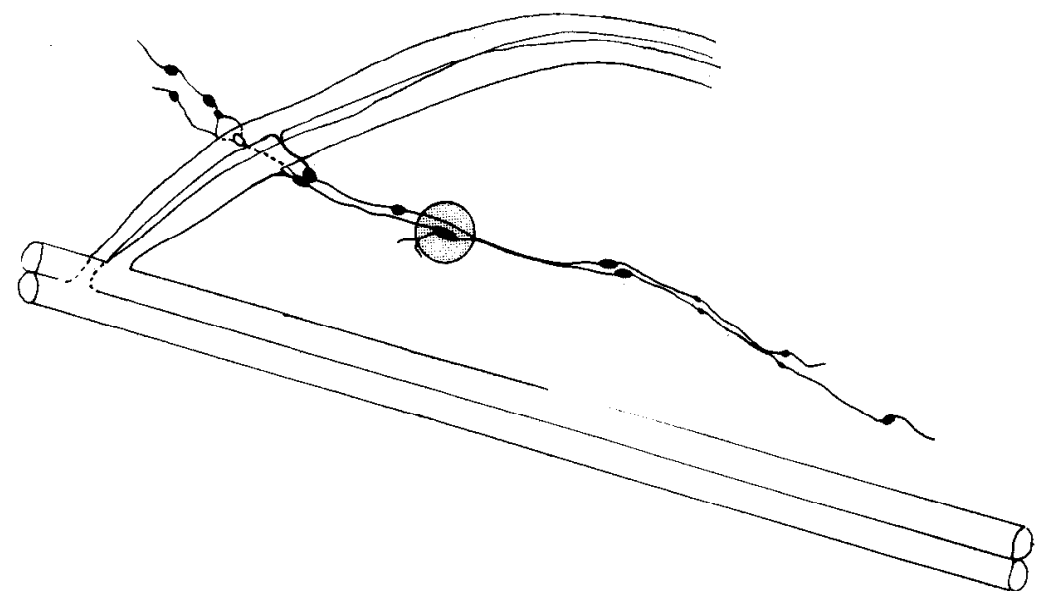

Site C2

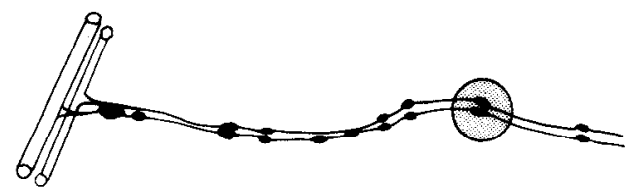

on a proximal muscle fiber, whereas the other two varicosities are from central fibers, and were selected to include two different locations along strings of varicosities. One was the first varicosity formed by the terminal (C1), and the other was located further along a string (C2) (Fig. 4). With all three varicosities, we were able to satisfy the requirements of electrophysiological recordings, bead labeling, and fixation for reconstruction analysis. Representative electron micrographs from the reconstructed varicosities are shown in Figure 5. The boundaries of the recording electrode can be measured accurately from the outlined ring of fluorescent beads, because the beads can be seen in the electron micrographs. Pre- and postsynaptic membranes are readily identinable by their electron densities, and the dense bodies of active zones appear as electron-dense hemispheres attached to the inner surface of the presynaptic membrane (Govind et al., 1994; Fig. 5B,C).

The maximal diameters of the three reconstructed varicosities were approximately $3-5 \mu \mathrm{m}$. In both proximal and central regions, the largest varicosities along the strings are usually the first ones formed by the axon terminals. The three reconstructed varicosities were rendered in digitized images, two of which are shown in pseudocolor in Figure $6, B$ and $C$. Each synapse is shown in a different color, and it is evident that synaptic areas vary greatly. In Figure $6, A$ and $B$ are of site $C 1$, whereas $C$ is of site P1; locations of these sites are shown in Figure 4 . Note that in Figure $6 C$, the varicosity sends out collaterals; this is characteristic of varicosities located on proximal muscle fibers.

Because of the difficultly in obtaining all the ultrathin sections during the serial reconstructions, the varicosities were not com-
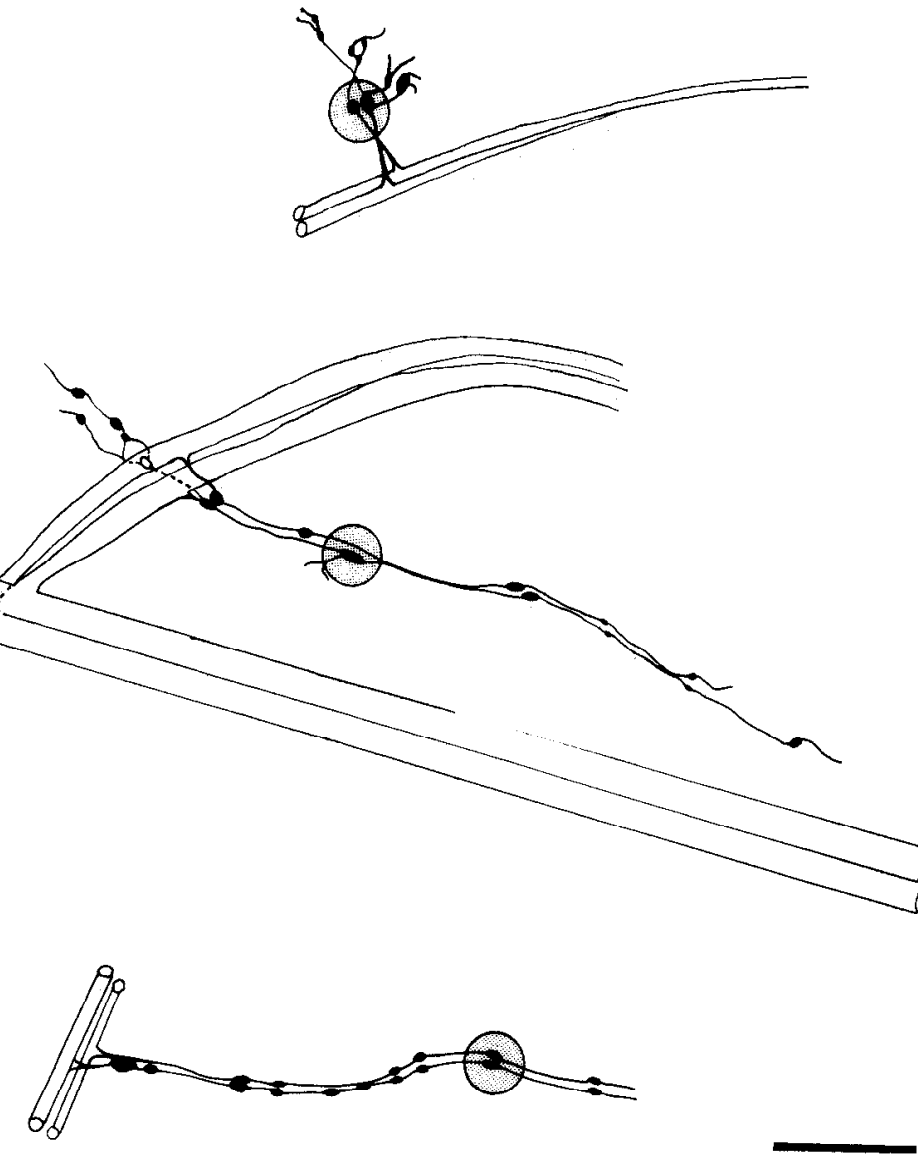

pletely reconstructed. For the three varicosities reported, the percentages of reconstruction are $87 \%(\mathrm{P} 1), 89 \%(\mathrm{C} 1)$, and $70 \%$ (C2). Quantitative structural measurements for these varicosities are described in Table 4. The most apparent structural differences nccur hetween the varicosity (P1) located on a proximal muscle fiber and the varicosity (C2) located on a central muscle fiber near the end of a string (Fig. 4). These differences are (1) in the number of synapses per terminal surface area, (2) in the number of dense bodies per terminal surface area, and (3) in the percentage of synapses with more than one dense body. The number of synapses per terminal surface area for $\mathrm{C} 2$ is double $\left(0.48 / \mu \mathrm{m}^{2}\right)$ that of P1 $\left(0.20 / \mu \mathrm{m}^{2}\right)$. In association with this, there are more dense bodies per terminal surface area in $\mathrm{C} 2(0.43 /$ $\left.\mu \mathrm{m}^{2}\right)$ than in P1 $\left(0.33 / \mu \mathrm{m}^{2}\right)$. However, P1 has a higher percentage of synapses with multiple dense bodies $(52 \%)$ than $\mathrm{C} 2$ $(17 \%)$. The varicosity (C1) that is close to the axon branch on a central muscle fiber shows more similarities with the proximal varicosity $(\mathrm{P} 1)$. In the number of synapses per terminal surface area, and in the number of dense bodies per terminal surface area, the two sites are identical. There is only a small difference in the number of synapses with multiple dense bodies between $\mathrm{P} 1(52 \%)$ and $\mathrm{C} 1(51 \%)$. These findings indicate that the terminals along a string may have a gradation in their synaptic ultrastructure, though more samples would be required to confirm this. The structural differences appear to correlate with lowfrequency transmission efficacy that was measured in this study. This is illustrated from sites C1 $(m=0.524)$ and P1 $(m=1.07)$, which have a greater mean quantal content than site C2 ( $m=$ 0.29 ; Tables 2,3 ). Site $\mathrm{C} 1$ has a higher $m$ value than any of the 

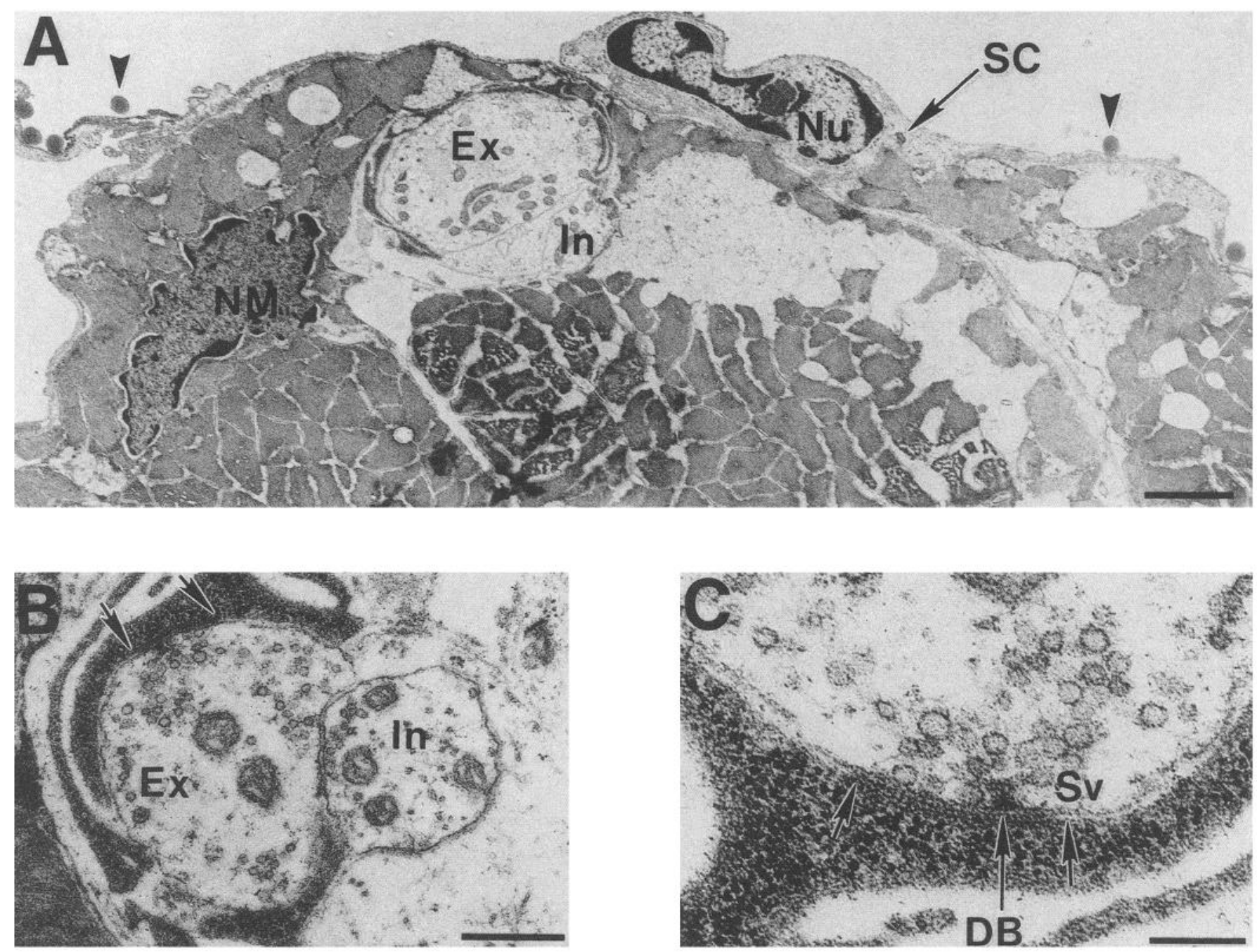

Figure 5. Electron micrographs from recording site C1. A, Electron-dense beads (arrowheads) deposited at the edges of the recording site over identified varicosities of the excitatory $(E x)$ and inhibitory $(I n)$ motor neurons. Other structures, including the muscle nucleus $(N M)$, satellite cells $(\mathrm{SC})$, and satellite cell nuclei $(\mathrm{Nu})$, are commonly seen associated with the neuromuscular junctions. $B$, Enlargement of $A$ in a subsequent section. Note the synaptic area (arrows) and the cluster of synaptic vesicles. $C$, The synaptic active zone is characterized by a dense body $(D B)$ and a closely associated cluster of synaptic vesicles $(S v)$. Scale bars: $A, 2.0 \mu \mathrm{m} ; B, 0.5 \mu \mathrm{m} ; C, 0.2 \mu \mathrm{m}$.

other varicosities selected on the central muscle; all of these were located more distally along strings of varicosities.

\section{$\mathrm{Ca}^{2+}$ signals}

Relative differences in fluorescence of $\mathrm{Ca}^{2+}$ indicators between high-output and low-output terminals were used to see if the degree of synaptic output could be related to differences in $\mathrm{Ca}^{2+}$ fluxes. Calcium green 2 and calcium green $5 \mathrm{~N} \mathrm{Ca}^{2+}$ indicators were tried with success. A typical response to stimulation of low-output and high-output terminals loaded with calcium green 2 is shown in Figure $6, D$ and $E$. Average relative changes in fluorescence responses are shown in Figure 7 for 21 central and 14 proximal terminals. The proximal terminals showed a greater percentage increase in fluorescence from rest to $2.5 \mathrm{~Hz}$, and from $5 \mathrm{~Hz}$ to $10 \mathrm{~Hz}$, than the central terminals $(p<0.05, t$ test).

Calcium green $5 \mathrm{~N}$ was used in the same manner as calcium green 2 . Since this indicator has a lower affinity for $\mathrm{Ca}^{2+}\left(K_{d}=\right.$ $3.3 \mu \mathrm{M})$ than calcium green $2\left(K_{d}=0.574 \mu \mathrm{M}\right)$, a greater concentration of $\mathrm{Ca}^{2+}$ is needed to produce a change in fluorescence. When calcium green $5 \mathrm{~N}$-loaded terminals were stimulated, slight changes in fluorescence of the axon and proximal varicosities were observed. Central terminals did not show an increase in fluorescence for the stimulation frequencies employed (data not shown). At stimulation frequencies higher than $10 \mathrm{~Hz}$, muscle movements hindered measurements. The results obtained with both indicators point to a relatively larger $\mathrm{Ca}^{2+}$ signal in proximal boutons at low stimulation frequencies.

\section{Discussion}

The principal finding of this article is that, in general, different synaptic endings of a single excitatory motor axon exhibit varying degrees of efficacy for an equivalent number of synapses. Present evidence indicates that this arises from differences in release probability that are correlated with relative intraterminal calcium buildup. The results of this study help to delimit the possibilities for physiological synaptic differentiation in a single neuron.

Since earlier reports of differences in EPSP amplitudes in a muscle innervated by a single excitatory motor neuron (Atwood, 1965; Iravani, 1965), there have been a number of investigations 

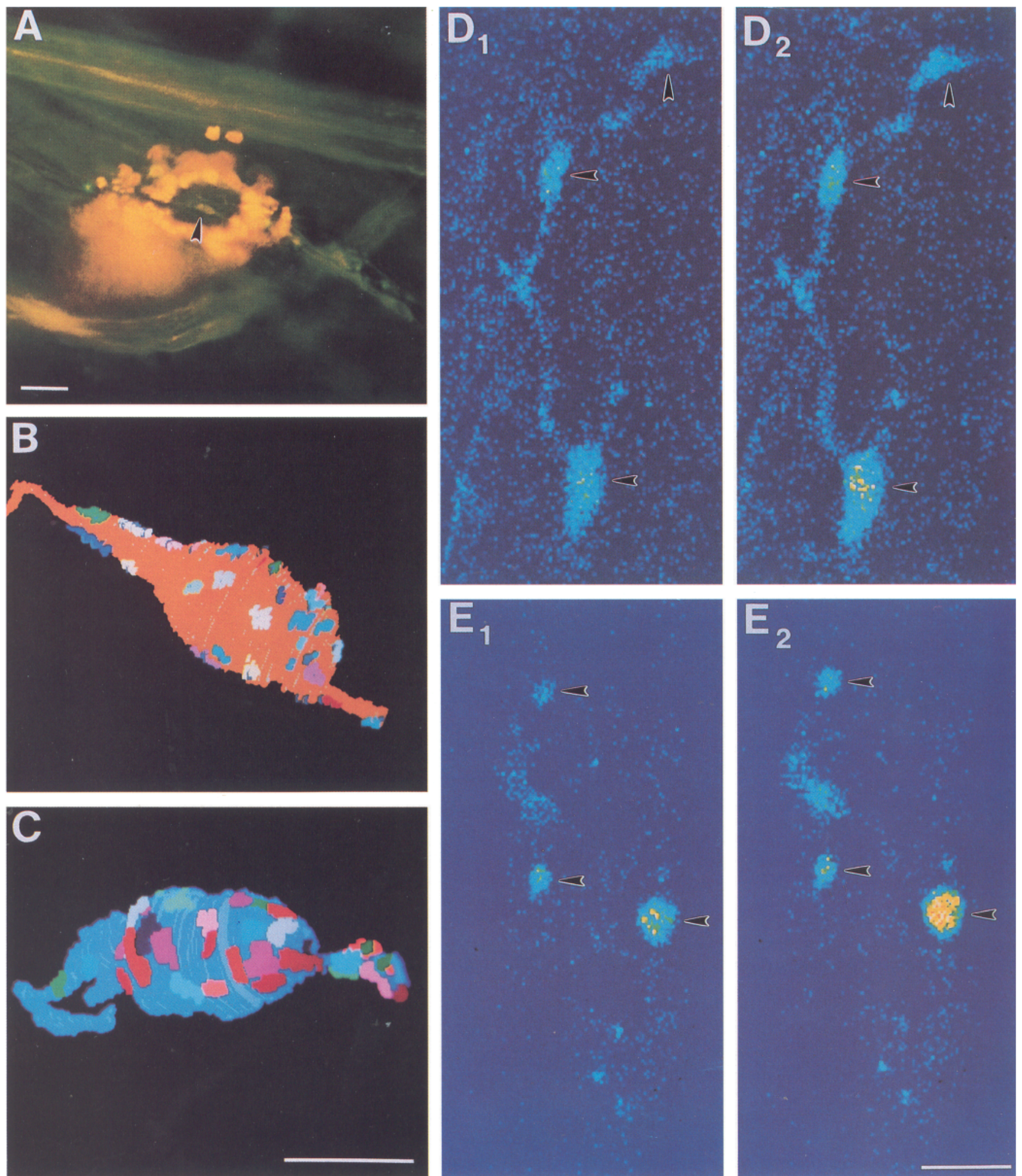

Figure 6. Labeling, reconstruction, and calcium imaging of motor nerve terminals. A, Fluorescence microscopy of a terminal varicosity stained with 4-Di-2-Asp and deposited fluorescent polystyrene beads, arranged in a ring around the varicosity. $B$, Varicosity shown in $A$ that was recorded and then reconstructed. $C$, Reconstruction of a varicosity on a proximal fiber (site P1) from which recordings were made. In both $B$ and $C$ the colored patches represent different synapses. $D$ and $E$, Calcium imaging of identified varicosities. Central $(D)$ and proximal $(E)$ terminals, loaded with calcium green, are shown at rest $(D 1$ and $E 1)$ and then at $10 \mathrm{~Hz}$ stimulation $(D 2$ and $E 2)$. Scale bars: $A, 20 \mu \mathrm{m} ; B$ and $C$, and $D$ and $E, 5$ $\mu \mathrm{m}$. 
Table 4. Structural characteristics measured at recorded and reconstructed terminal varicosities

\begin{tabular}{|c|c|c|c|}
\hline \multirow[b]{2}{*}{$\underline{\text { Terminal morphology }}$} & \multirow{2}{*}{$\begin{array}{l}\text { Proximal } \\
\text { Site P1 }\end{array}$} & \multicolumn{2}{|l|}{ Central } \\
\hline & & Site C1 & Site $\mathrm{C} 2$ \\
\hline \multicolumn{4}{|l|}{ Synapses } \\
\hline$\%$ of labeled site reconstructed & 87 & 89 & 70 \\
\hline \# of ultrathin sections & 194 & 258 & 165 \\
\hline Terminal length analyzed $(\mu \mathrm{m})$ & 20 & 19.8 & 12.7 \\
\hline Surface area of terminal analyzed $\left(\mu \mathrm{m}^{2}\right)$ & 142.9 & 155.4 & 73 \\
\hline \# of all synapses & 29 & 31 & 35 \\
\hline \# of complete synapses & 22 & 19 & 23 \\
\hline \# of incomplete synapses & 7 & 12 & 12 \\
\hline \# of all synapses/terminal surface area & 0.20 & 0.20 & 0.48 \\
\hline Mean surface area of all synapses $\left(\mu \mathrm{m}^{2}\right.$, mean $\left.\pm \mathrm{SE}\right)$ & $0.51 \pm 0.04$ & $0.44 \pm 0.04$ & $0.28 \pm 0.03$ \\
\hline of complete synapses & $0.52 \pm 0.04$ & $0.44 \pm 0.04$ & $0.30 \pm 0.04$ \\
\hline of incomplete synapses & $0.47 \pm 0.06$ & $0.45 \pm 0.07$ & $0.24 \pm 0.07$ \\
\hline \multicolumn{4}{|l|}{ Active zone specializations } \\
\hline \# of dense bodies & 45 & 49 & 31 \\
\hline Dense bodies/terminal surface area $\left(\mu \mathrm{m}^{2}\right)$ & 0.33 & 0.33 & 0.43 \\
\hline \multicolumn{4}{|l|}{$\begin{array}{l}\text { \# of all synapses with and without active zones (\% of total) } \\
\text { Dense bodies }\end{array}$} \\
\hline 0 & $3(10 \%)$ & $1(3 \%)$ & $11(31 \%)$ \\
\hline 1 & $11(38 \%)$ & $14(45 \%)$ & $18(51 \%)$ \\
\hline 2 & $11(38 \%)$ & $15(48 \%)$ & $5(14 \%)$ \\
\hline 3 & $1(11 \%)$ & & $1(3 \%)$ \\
\hline 4 & & - & \\
\hline 5 & & $1(3 \%)$ & \\
\hline \multicolumn{4}{|l|}{$\begin{array}{l}\text { \# of complete synapses with and without active zones } \\
\text { (\% of total) }\end{array}$} \\
\hline \multicolumn{4}{|l|}{ Dense bodies } \\
\hline 0 & $2(9 \%)$ & $1(5 \%)$ & $7(31 \%)$ \\
\hline 1 & $8(36 \%)$ & $10(53 \%)$ & $12(52 \%)$ \\
\hline 2 & $8(36 \%)$ & $8(42 \%)$ & $3(13 \%)$ \\
\hline 3 & $4(28 \%)$ & & $1(4 \%)$ \\
\hline \multicolumn{4}{|l|}{$\begin{array}{l}\text { Mean synaptic area for synapses with different complements } \\
\text { of active zones for all synapses }\left(\mu \mathrm{m}^{2}, \text { mean } \pm \text { SE) }\right.\end{array}$} \\
\hline \multicolumn{4}{|l|}{ Dense bodies } \\
\hline 0 & $0.44 \pm 0.04$ & 0.16 & $0.12 \pm 0.03$ \\
\hline 1 & $0.41 \pm 0.06$ & $0.34 \pm 0.04$ & $0.30 \pm 0.04$ \\
\hline 2 & $0.55 \pm 0.05$ & $0.52 \pm 0.05$ & $0.51 \pm 0.12$ \\
\hline 3 & $0.71 \pm 0.10$ & - & 0.44 \\
\hline 4 & & - & \\
\hline 5 & & 0.96 & \\
\hline \multicolumn{4}{|l|}{ For complete synapses $\left(\mu \mathrm{m}^{2}\right.$, mean $\left.\pm \mathrm{SE}\right)$} \\
\hline \multicolumn{4}{|l|}{ Dense bodies } \\
\hline 0 & $0.45 \pm 0.07$ & 0.16 & $0.15 \pm 0.03$ \\
\hline 1 & $0.43 \pm 0.07$ & $0.34 \pm 0.04$ & $0.34 \pm 0.04$ \\
\hline 2 & $0.54 \pm 0.06$ & $0.60 \pm 0.05$ & $0.43 \pm 0.11$ \\
\hline 3 & $0.71 \pm 0.10$ & & 0.44 \\
\hline
\end{tabular}

Data are morphological characteristics of reconstructed varicosities from proximal and central regions of the opener muscle.

to elucidate the mechanisms that may explain this phenomenon. Atwood (1967) showed differences in synaptic currents at endings of a crab motor neuron, and suggested differences in action potential related nerve terminal depolarization as a mechanism. Bittner (1968a, Table II) surveyed the dorsal superficial muscle fibers of the crayfish opener muscle and reported an average 14fold difference between central and distal regions. Similarly, our investigation of the ventral superficial muscle fibers showed an average eightfold difference between proximal and central fi- bers, the same as reported by Iravani (1965) in the crayfish $A s$ tacus fluviatilis. Bittner (1968a) concluded that input resistance of the muscle fibers could only account for a small amount of the difference in the EPSP amplitudes and that the major contributing factor was a difference in presynaptic efficacy possibly arising from a more effective invasion of the distal presynaptic nerve terminals by the nerve impulse at low frequencies. This hypothesis was based on evidence of decremental conduction in crayfish nerve terminals (Dudel, 1963, 1965, 1981), which has 


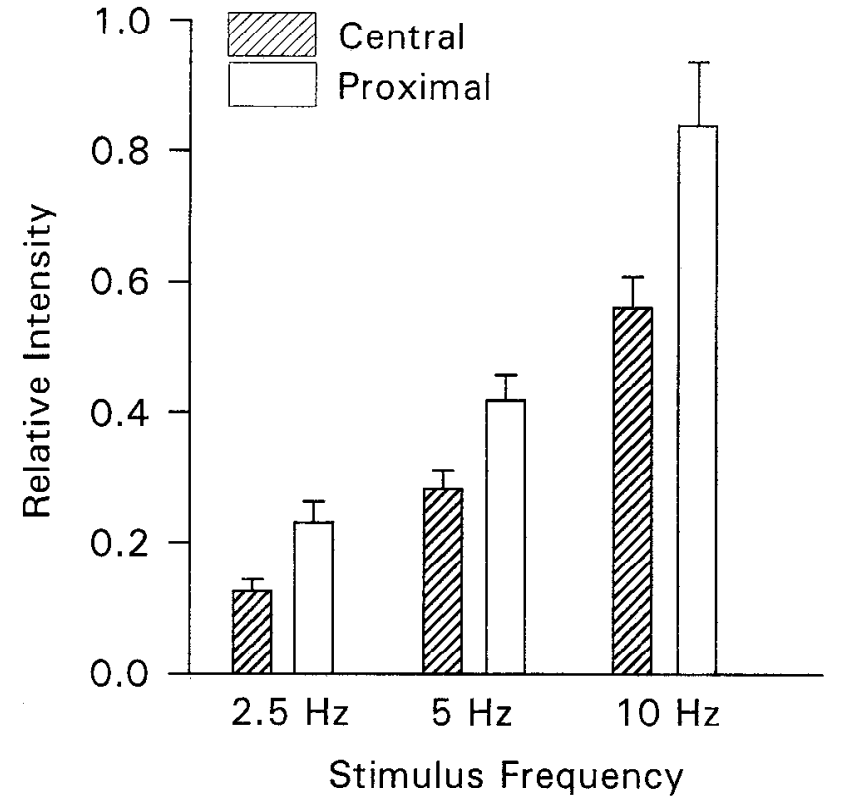

Figure 7. Relative changes in fluorescence $\left[\left(F_{\text {Stim }}-F_{\text {Rest }}\right) /\left(F_{\text {Res }}\right)\right]$ at central low-output and proximal high-output varicosities at increasing frequencies of stimulation, in several preparations loaded with calcium green 2. Calcium entry, as indicated by relative change in fluorescence, is significantly greater in proximal varicosities $(p<0.05)$. Means $( \pm \mathrm{SE})$ of 21 central and 14 proximal varicosities are shown.

been discussed as a plausible explanation for differences in highand low-output terminals in this and other crustacean muscles (Atwood, 1967; Atwood and Johnston, 1968; Sherman and Atwood, 1972; Dudel, 1981). The results of Zucker (1974), who focally stimulated preterminal areas and obtained evidence for active responses, told against this possibility, but since the stimulated structures were not visualized, the interpretation of the observations remains somewhat open, particularly in view of contrary evidence (Dudel, 1981). Our present results do not rule out differences in nerve terminal electrical events, but we can now extend the available possibilities to include differences in ultrastructure and in presynaptic calcium buildup.

We assessed the extent to which postsynaptic properties could account for the difference in EPSP amplitude. The differences in muscle fiber input resistance $\left(R_{\text {in }}\right)$ values paralleled the amplitudes of the EPSPs, but could only account for a twofold difference (Cooper et al., 1993). This finding is in general agreement with earlier studies on leg muscles of several crustacean species (Atwood and Dorai Raj, 1964; Bittner, 1968a; Sherman and Atwood, 1972; Meiss and Govind, 1979).

Since the various studies agree that the major difference must be in presynaptic properties, we studied synaptic efficacy with macropatch recordings placed on visualized terminal varicosities of muscle fibers with different EPSP amplitudes. In general, mean quantal content of individual proximal terminal varicosities was larger than for central varicosities. At higher frequencies, the percentage change in mean quantal content was larger for terminals on central fibers, indicating that they were able to increase synaptic output to a greater extent than proximal terminals to meet transmission demands at higher frequencies (Bittner, 1968a). Since proximal terminals generate a higher quantal output at minimal frequencies of stimulation than central ones, they may have less ability to further increase their output at higher frequencies. Varicosities along the terminal strings on the central muscle fibers decrease in size distally; transmitter release at low frequencies correspondingly decreases. A similar observation on differences in transmitter release along a terminal has been made at frog neuromuscular junctions (Bennett and Lavidis, 1982; Bennett et al., 1986). Change in varicosity size with position along the length of the string probably arises in crustaceans during development and growth (Govind, 1982).

Synapse counts for reconstructed varicosities showed more individual synapses for varicosities with lower output, but when the total synaptic surface area per varicosity is taken into consideration, the varicosities with higher synaptic output have a greater synaptic surface area. The parts of the terminal between the varicosities do not contribute extensively to synaptic output since relatively few synapses occur there (Jahromi and Atwood, 1974; Florey and Cahill, 1982). Our ultrastructural data support earlier findings by Govind et al. (1994) that there are more dense bodies (active zones) per synapse in terminals on proximal than on central muscle fibers. In our samples, we did not find differences in active zone lengths in the two regions, as reported previously (Govind et al., 1994). It fact, it is difficult to accurately determine lengths of presynaptic dense bodies that are less than the width of two ultrathin sections. This problem arises from the mechanics of projecting objects from 3-D space onto a 2-D viewing screen, as is done with serial sections derived from transmission electron microscopy (Pfenninger et al., 1969; Underwood, 1970; Vrensen et al., 1980).

The number of active zones per synapse may give an indication of a particular synapse's ability to release transmitter at low frequencies of activation. Synapses with more than one dense body we term "complex," and those with one or no dense bodies, "simple" synapses. The percentage of complex synapses was greater in the high-output varicosities. Although only three sites were obtained in this study for which direct correlations of structure and function can be put forth, the indication is strong that a higher number of active zones per terminal surface area and a higher percentage of complex synapses may be linked to a greater synaptic output at low frequencies. These results complement the recent reports of Govind et al. (1994) and Wojtowicz et al. (1994) based upon more extensive sampling in which greater numbers of complex synapses were found in regions that exhibited higher synaptic output. The number of individual synapses is not correlated with low-frequency transmitter output, since site $\mathrm{C} 2$ has the largest number of synapses per terminal surface area and the lowest quantal content. However, the percentage of complex synapses is less for this site, and the percentage of synapses without any discernable active zones is greater. This again supports the interpretation that the quantal output at low frequencies depends upon the contribution of the complex synapses.

The general finding in this and earlier studies (Wojtowicz et al., 1991, 1994; Govind et al., 1994) has been that there are many more synapses on a varicosity than the values of $n$ (putative number of active synapses) calculated at low frequencies from statistical models based on binomial distributions. The hypothesis arising from these data is that there may be recruitment of previously silent synapses when a demand arises, as would occur with higher frequencies of stimulation. If a few complex synapses are selectively active at low frequencies, the simple synapses may be progressively recruited at higher frequencies or with prolonged activity, thereby providing part of the very large increase in transmission that is observed.

The $\mathrm{Ca}^{2+}$ indicator fluorescence measurements suggest that a 
higher concentration of free $\mathrm{Ca}^{2+}$ ions is generated in high-output terminals than in low-output ones of a single neuron for low frequencies of stimulation. In the present study, only relative changes in $\mathrm{Ca}^{2+}$ were measured, and the indicator employed could not provide the absolute $\mathrm{Ca}^{2+}$ concentrations with ratiometric methods. Despite this, the high-output terminals had relatively larger changes in fluorescence during stimulation. These results are in contrast to a recent report by Delaney and Tank (1994) in which no difference was seen in $\mathrm{Ca}^{2+}$ buildup or recovery between proximal and central terminals during or after tetanic stimulation at $15 \mathrm{~Hz}$. Possible differences were attributed to differences in surface area to volume ratios among the varicosities. In our studies, we found that normalizing the $\mathrm{Ca}^{2+}$ indicator fluorescence signals to surface area or to volume does not alter the results and that there is still a significant difference between relative $\mathrm{Ca}^{2+}$ signals in varicosities of the two regions. More $\mathrm{Ca}^{2+}$ entry would be expected to result in a grcater mean quantal content. In recent work on mammalian central synapses, evidence for differing probabilities of transmitter release at individual boutons, possibly linked to differences in calcium entry, has been put forward (Malinow et al., 1994). Studies by Parnas et al. (1982b) on crayfish terminals have raised the possibility that differences in resting $\mathrm{Ca}^{2+}$ levels, if they exist, could explain aspects of the physiological differences in high- and low-output terminals. Such differences could in principle arise from regional variations in $\mathrm{Ca}^{2+}$ buffering or extrusion. However, the degrec of difference in resting $\mathrm{Ca}^{2+}$ levels required to account for the physiological effects is substantial. Our measurements do not permit an absolute comparison of $\mathrm{Ca}^{2+}$ concentrations in the terminals we observed, but we did not see anything that would suggest a substantial regional difference in resting $\mathrm{Ca}^{2+}$ concentrations, nor has such a difference been reported by other authors (Zucker, 1974; Delaney et al., 1991). Thus, at present, a substantial regional difference in resting $\mathrm{Ca}^{2+}$ concentrations seems unlikely.

The reason for a difference in $\mathrm{Ca}^{2+}$ entry must be further investigated. Each crayfish synapse appears to have relatively few $\mathrm{Ca}^{2+}$ channels (Govind et al., 1994) and the probability of channel opening during an action potential is not known for this system. In the chick ciliary ganglion terminals, the probability appears to be quite low (Stanley, 1992). The channel behavior may be different for low- and high-output terminals. It is not known whether all the large membrane particles at an active zone (Govind et al., 1994) are equipotent calcium channels, or whether a varying proportion of them are calcium-activated potassium channels known to occur at active zones of vertebrate hair cells (Roberts et al., 1990; Issa and Hudspeth, 1994). Calcium-activated $\mathrm{K}^{+}$conductance has been reported at the frog neuromuscular junction (Robitaille and Charlton, 1992) and in crayfish terminals (Sivaramakrishnan et al., 1991a,b). Comparative behavior and occurrence of channels at different presynaptic nerve endings are relatively unexplored topics.

In view of these uncertainties, several possibilities that could account for the observed differences in $\mathrm{Ca}^{2+}$ buildup and transmission remain open. These could include, either alone or in combination, (1) more activatable calcium channels at higheroutput synapses, (2) possible differences in calcium sequestration or extrusion, and (3) differences in electrical events in the varicosities. The latter possibility must be kept alive in view of recent sludies on the variation of electrical events in mammalian dendrites (Major et al., 1994; Markram and Sakman, 1994).

\section{References}

Atwood HL (1965) Characteristics of fibres in the extensor muscle of a crab. Comp Biochem Physiol 14:205-207.

Atwood HL (1967) Variation in physiological properties of crustacean motor synapses. Nature 215:57-58.

Atwood HL, Bittner GD (1971) Matching of excitatory and inhibitory inputs to crustacean muscle fibers. J Neurophysiol 34:157-170.

Atwood HL, Dorai Raj BS (1964) Tension development and membrane responses in phasic and tonic muscle fibers of a crab. $\mathbf{J}$ Cell Comp Physiol 64:55-72.

Atwood HL, Johnston HS (1968) Neuromuscular synapses of a crab motor axon. J Exp Zool 167:457-470.

Atwood HL, Parnas I (1968) Recording from the crayfish abdominal extensor muscle preparation with microelectrodes. In: Experiments in physiology and biochemistry (Kerkut GA, ed), pp 307-330. London: Academic.

Atwood HL, Cooper RL, Wojtowicz JM (1994) Non-uniformity and plasticity of quantal release at crustacean motor nerve terminals. In: Advances in second messenger and phosphoprotein research, Molecular and cellular mechanisms of neurotransmitter release (Stjärne L, Greengard P, Grillner SE, Hökfelt TGM, Ottoson DR, eds), pp 363382. New York: Raven.

Bckkers JM, Stevens CF (1991) Excitatory and inhibitory autaptic currents in isolated hippocampal neurons maintained in cell culture. Proc Natl Acad Sci USA 88:7834-7838.

Bennett MR, Lavidis NA (1982) Variation in quantal secretion at different release sites along developing and mature motor terminal branches. Dev Brain Res 5:1-9.

Bennett MR, Jones P, Lavidis NA (1986) The probability of quantal secretion along visualized terminal branches at amphibian (Bufo marinus) neuromuscular synapses. J Physiol (Lond) 379:257-274.

Bittner GD (1968a) Differentiation of nerve terminals in the crayfish opener muscle and its functional significance. J Gen Physiol 51:731758.

Bittner GD (1968b) The differentiation of crayfish muscle fibers during development. J Exp Zool 167:439-456.

Bittncr GD, Kennedy D (1970) Quantitative aspects of transmitter release. J Cell Biol 47:585-592.

Cooper RL, Wojtowicz JM, Atwood HL (1993) High- and low-output synapses of a single crustacean motor axon. Soc Neurosci Abstr 19: 88.1 .

Cooper RL, Stewart BA, Wojtowicz JM, Wang S, Atwood HL (1995) Quantal measurement and analysis methods compared for crayfish and Drosophila neuromuscular junctions and rat hippocampus. J Neurosci Methods, in press.

Delaney K, Tank DW (1994) A quantitative measurement of the dependence of short- term synaptic enhancement on presynaptic residual calcium. J Neurosci 14:5885-5902.

Delaney K, Tank DW, Zucker RS (1991) Presynaptic calcium and serotonin-mediated enhancement of transmitter release at crayfish neuromuscular junction. J Neurosci 11:2631-2643.

Dudel J (1963) Presynaptic inhibition of the excitatory nerve terminals in the neuromuscular junction of the crayfish. Pfluegers Arch 277 : 537-557.

Dudel J (1965) Potential changes in the crayfish motor nerve terminal during repetitive stimulation. Pfluegers Arch 282:323-337.

Dudel J (1981) The effect of reduced calcium on quantal unit current and release at the crayfish neuromuscular junction. Pfluegers Arch 391:35-40.

Dudel J (1989a) Calcium dependence of quantal release triggered by graded depolarization pulses to nerve terminals on crayfish and frog muscle. Pfluegers Arch 415:289-298.

Dudel J (1989b) Shifts in the voltage dependence of synaptic release due to changes in the extracellular calcium concentration at nerve terminals on muscle of crayfish and frogs. Pflucgers Arch 415:299303.

Dudel J (1989c) Calcium and depolarization dependence of twin-pulse facilitation of synaptic release at nerve terminals of crayfish and frog muscle. Pfluegers Arch 415:304-309.

Dudel J (1989d) Twin pulse facilitation in dependence on pulse duration and calcium concentration at motor nerve terminals of crayfish and frogs. Pfluegers Arch 415:310-315.

Dudel J, Kuffler SW (1961) The quantal nature of transmission and spontaneous miniature potentials at the crayfish neuromuscular junction. J Physiol (Lond) 155:514-529. 
Efron B (1979) Bootstrap methods: another look at the jackknife. Ann Stat 7:1-26.

Efron B, Tibshirani R (1993) The bootstrap estimate of standard error. In: An introduction to the bootstrap (Efron B, Tibshirani R, eds), pp 45-59. New York: Chapman \& Hall.

Florey E, Cahill MA (1982) The innervation pattern of crustacean skeletal muscle. Cell Tissue Res 224:527-541.

Govind CK (1982) Development of nerve, muscle and synapse. In: The biology of crustacea, Vol 3, Neurobiology: structure and function (Bliss DE, Atwood HL, Sandeman DC, eds), pp 185-204. Ncw York: Academic.

Govind CK, Pearce J, Wojtowicz JM, Atwood HL (1994) "Strong" and "weak" synaptic differentiation in the crayfish opener muscle: structural correlates. Synapse 16:45-58.

Harrington CC (1993) An investigation of structural relationships of the crayfish neuromuscular junction. MS thesis, University of Toronto.

Hessler NA, Shirke AM, Malinow R (1993) The probability of transmitter release at a mammalian central synapse. Nature 366:569-572.

Hochner B, Parnas H, Parnas I (1989) Membrane depolarization evokes neurotransmitter release in the absence of calcium entry. Nature 342 : $433-435$.

Iravani J (1965) Membrandepolarisation der Muskelfasern des Öffnermuskels des Flusskrebses au斤 Nervenreiz und Kaliumapplikation. Experientia 21:609-610.

Issa N, Hudspeth AJ (1994) Clustering of $\mathrm{Ca}^{2+}$ channels and $\mathrm{Ca}^{2+}$ activated $\mathrm{K}^{+}$channels at fluorescently labeled presynaptic active zones of hair cells. Proc Natl Acad Sci USA 91:7578-7582.

Jahromi SS, Atwood HL (1974) Three-dimensional ultrastructure of the crayfish neuromuscular apparatus. J Cell Biol 63:599-613.

Katz PS, Kirk MD, Govind CK (1993) Facilitation and depression at different branches of the same motor axon: evidence for presynaptic differences in release. J Neurosci 13:3075-3089.

Korn H, Faber DS, Triller A (1986) Probabilistic determination of synaptic strength. J Neurophysiol 55:402-421.

Lavidis NA, Bennett MR (1992) Probabilistic secretion of quanta from visualized sympathetic nerve varicosities in mouse vas deferens. $J$ Physiol (Lond) 454:9-26.

Linder TM (1974) The accumulative properties of facilitation at crayfish neuromuscular synapses. J Physiol (Lond) 238:223-234.

Magrassi L, Purves D, Lichtman JW (1987) Fluorescent probes that stain living nerve terminals. J Neurosci 7:1207-1214.

Major G, Larkman AU, Ionas P, Sakmann B, Jack IJB (1994) Detailed passive cable models of whole-cell recorded $\mathrm{CA} 3$ pyramidal neurons in rat hippocampal slices. J Neurosci 14:4613-4638.

Malinow R, Otmakhov N, Blum KL, Lisman J (1994) Visualizing hippocampal synaptic function by optical detection of $\mathrm{Ca}^{2+}$ entry through the $N$-methyl-D-aspartate channel. Proc Natl Acad Sci USA 91:8170-8174.

Markram H, Sakman B (1994) Calcium transients in dendrites of neocortical neurons evoked by single subthreshold excitatory postsynaptic potentials via low-voltage-activated calcium channels. Proc Natl Acad Sci USA 91:5207-5211.

Martin AR (1977) Junctional transmission. II. Presynaptic mechanisms. In: The handbook of physiology, The nervous system, Vol 1, Cellular biology of neurons, Pt 1, pp 329-355. Bethesda, MD: American Physiological Society.

Meiss DE, Govind CK (1979) Regional differentiation of neuromuscular synapses in a lobster receptor muscle. J Exp Biol 79:99-114.

Parnas I, Parnas H, Dudel J (1982a) Neurotransmitter release and its facilitation in crayfish. II. Duration of facilitation and removal processes of calcium from the terminal. Pfluegers Arch 393:232-236.

Parnas I, Parnas H, Dudel J (1982b) Neurotransmitter release and its facilitation in crayfish muscle. V. Basis for synapse differentiation of the fast and slow type in one axon. Pfluegers Arch 395:261-270.

Pfenninger K, Sandri C, Akert K, Eugster CH (1969) Contribution to the problem of structural organization of the presynaptic area. Brain Res 12:10-18

Pierce JP, Mendell (1993) Quantitative ultrastructure of Ia boutons in the ventral horn: scaling and positional relationships. J Neurosci 13: $4748-4763$.

Roberts WM, Jacobs RA, Hudspeth AJ (1990) Colocalization of ion channels involved in frequency selectivity and synaptic transmission at presynaptic active zones of hair cells. J Neurosci 10:3664-3684.

Robitaille R, Charlton MP (1992) Presynaptic calcium signals and transmitter release are modulated by calcium-activated potassium channels. J Neurosci 12:297-305.

Rosenmund C, Clements JD, Westbrook GL (1993) Nonuniform probability of glutamate release at a hippocampal synapse. Science 262: 754-757.

Sherman RG, Atwood HL (1972) Correlated electrophysiological and ultrastructural studies of a crustacean motor unit. J Gen Physiol 59: $586-615$.

Sivaramakrishnan S, Bittner GD, Brodwick MS (1991a) Calcium-activated potassium conductance in presynaptic terminals at the crayfish neuromuscular junction. J Gen Physiol 98:1161-1179.

Sivaramakrishnan S, Brodwick MS, Bittner GD (1991b) Presynaptic facilitation at the crayfish neuromuscular junction: role of calciumactivated potassium conductance. J Gen Physiol 98:1181-1 196.

Smith BR, Wojtowicz JM, Atwood HL (1991) Maximum likelihood estimation of non-uniform transmitter release probabilities at the crayfish neuromuscular junction. J Theor Biol 150:457-472.

Stanley EF (1992) The calyx-type synapse of the chick ciliary ganglion as a model of fast cholinergic transmission. Can J Physiol Pharmacol [Suppl] 70:S73-S77.

Stewart BA, Cooper RL, Wojtowicz JM, Wang S, and Atwood HL (1994) Comparison of quantal analysis methods at crayfish, Drosophila and rat hippocampal synapses: measurements of charge, amplitude and direct counts of events. Soc Neurosci $\Lambda$ bstr 20:549.7.

Stühmer W, Almers W (1982) Photobleaching through glass micropipettes: sodium channels without lateral mobility in the sarcolemma of frog skeletal muscle. Proc Natl Acad Sci USA 79:946-950.

Thompson CS, Atwood HL (1984) Synaptic strength and horseradish peroxidase uptake in crayfish nerve terminals. J Neurocytol 13:267280.

Underwood EE (1970) Quantitative stereology. Reading, MA: Addison-Wesley.

Van der Kloot W (1991) The regulation of quantal size. Prog Neurobiol 36:93-130.

Vrensen G, Cardozo JN, Müller L, Van der Want J (1980) The presynaptic grid: a new approach. Brain Res 184:23-40.

Walrond JP, Govind CK, Heustis S (1993) Two structural adaptations for regulating transmitter release at lobster neuromuscular synapses J Neurosci 13:4831-4845.

Wernig A (1972) Changes in statistical parameters during facilitation at the crayfish neuromuscular junction. J Physiol (Lond) 226:751 759.

Wiens TJ (1985) Triple innervation of the crayfish opener muscle: the astacuran common inhibitor. J Neurobiol 16:183-191.

Wiersma CAG (1961) The neuromuscular system. In: The physiology of crustacea, Vol 2 (Waterman TH, ed), pp 191-240. New York: Academic

Wojtowicz JM, Atwood HL (1984) Presynaptic membrane potential and transmitter release at the crayfish neuromuscular junction. J Neurophysiol 52:99-113.

Wojtowicz JM, Atwood HL (1986) Long-term facilitation alters transmitter releasing properties at the crayfish neuromuscular junction. $J$ Neurophysiol 55:484-498.

Wojtowicz JM, Smith BR, Atwood HL (1991) Activity-dependent recruitment of silent synapses. Ann NY Acad Sci 627:169-179.

Wojtowicz JM, Marin L, Atwood HL (1994) Activity-induced changes in synaptic release sites at the crayfish neuromuscular junction. $J$ Neurosci 14:3688-3702

Young SJ, Royer SM, Groves PM, Kinnamon JC (1987) Three-dimensional reconstructions from serial micrographs using the IBM PC. J Electron Microsc 6:207-217.

Zucker RS (1974) Excitability changes in crayfish motor neurone terminals. J Physiol (Lond) 241:111-126.

Zucker RS, Haydon PG (1988) Membrane potential has no direct role in evoking neurotransmitter release. Nature 335:360-362. 